\title{
Developmental Lead Exposure Alters the Stimulatory Properties of Cocaine at PND 30 and PND 90 in the Rat
}

\author{
Jack R. Nation, Ph.D., Dennis K. Miller, Ph.D., and Gerald R. Bratton, D.V.M., Ph.D.
}

The aim of this study was to examine the effects of perinatal lead exposure on locomotor responding following acute and repeated cocaine challenges (sensitization). Adult female rats were gavaged daily with 0,8 , or $16 \mathrm{mg}$ lead acetate for 30 days prior to breeding. This exposure regimen was maintained throughout gestation and lactation (perinatal exposure). On Day 21, male pups were weaned and lead exposure was discontinued for the remainder of the study. Beginning on postnatal day (PND) 30 or PND 90, and continuing for 14 successive days, separate groups of perinatally-exposed animals were presented with challenges of $10 \mathrm{mg} / \mathrm{kg}$ cocaine $\mathrm{HCl}$ (i.p.), and tested for locomotor responding. Following this testing period, dose-effect profiles were determined, with animals receiving daily injections of $0,10,20$, and $40 \mathrm{mg} / \mathrm{kg}$ cocaine. The results indicated that both at PND 30 and PND 90 lead-exposed animals were less responsive to the initial administration of cocaine, but exhibited a supersensitivity to the stimulatory effects associated with repeated administration of cocaine, i.e., behavioral sensitization to cocaine was augmented by perinatal lead exposure. Analyses of blood lead levels following the completion of testing revealed that lead levels were below detectable limits for all animals $(<1 \mu \mathrm{g} / \mathrm{dl})$. Collectively, these findings show that developmental lead contamination produces changes in cocaine sensitivity long after exposure has been discontinued and the toxicant has gained clearance from blood.

[Neuropsychopharmacology 23:444-454, 2000] (C) 2000 American College of Neuropsychopharmacology. Published by Elsevier Science Inc.
KEY WORDS: Activity; Cocaine; Development; Lead; Sensitization

Lead poisoning continues to present major health concerns nationwide, and this situation is especially problematic among children. Recent sociodemographic data indicate the threat of lead toxicity is especially great among economically disadvantaged, nonwhite, and inner-city children (Goldman and Carra 1994; Pirkle et al. 1994). Along these lines, a 1999 report alarmingly places

From the Department of Psychology (JRN, DKM) and Department of Veterinary Anatomy and Public Health (GRB), Texas A\&M University, College Station, TX.

Address correspondence to: Dr. Jack R. Nation, Department of Psychology, Texas A\&M University, College Station, TX 77843.

Received October 15, 1999; revised March 10, 2000; accepted March 17, 2000. the "at risk" figure for children suffering from excessive lead exposure at around $70 \%$ in major metropolitan areas of the United States (cf., Mielke 1999).

The sizable literature on developmental lead poisoning understandably has focused on global disturbances produced by early contaminant exposure that may have an enduring impact on the quality of life. In this sense, the data are compelling with respect to showing that even low-level lead exposure during development can occasion long-lasting neurobehavioral disturbances that compromise adult adaptive abilities and threaten stability. In this regard, functional deficits in cognitive and intellectual processing have been shown to persist well into the adult cycle of humans, rodents, and nonhuman primates (e.g., Bellinger et al. 1987). In addition, it seems that even emotional expression and attendant psychosocial phenomena may be influenced by lead ex- 
posure during early development (Needleman et al. 1996).

In the present report, our objective was to investigate interactive relations between developmental lead exposure and drug sensitivity later in the life cycle. This is an especially pertinent issue given that lead uniquely threatens sub-populations where drug abuse is more common, i.e., urban minorities (Brody et al. 1994). Clearly, experiential elements, availability, drug history, poverty, etc., must be considered in the list of dispositional factors that determine drug habits in humans. But it also must be considered that other types of environmental events may contribute to the abuse potential of selective drugs. That is, to the extent that lead or any other xenobiotic chemical alters the impact of a set delivery of a drug, motivational features related to drug seeking and taking may be redefined and therein influence maintenance responding and/or the effectiveness of certain pharmacotherapies for drug abuse (Mello et al. 1995).

The development of behavioral sensitization during repeated administration of psychomotor stimulants is a well-characterized phenomenon which has received considerable attention because of its proposed relevance to drug addiction (Robinson and Berridge 1993; Wise and Bozarth 1987; Wolf et al. 1995) and psychosis (Post et al. 1992; Segal and Schuckit 1983). Therefore, the procedure was employed here in an effort to determine the effects of lead exposure during lactation and gestation on cocaine-induced changes in locomotor responding during periadolescence and adulthood. Specifically, beginning on postnatal day (PND) 30 or PND 90, male rats perinatally exposed to lead were monitored in activity chambers following acute and repeated experience with cocaine.

\section{MATERIALS AND METHODS}

\section{Animals and Exposure Regimen}

All aspects of the research reported here were approved by the University Laboratory Animal Care Committee. Adult female Sprague-Dawley female rats (Charles River) were matched on initial body weight across groups. Each female rat was gavaged daily with 0 (sodium acetate), 8 , or $16 \mathrm{mg}$ lead acetate using a 16 gauge gavage needle to administer the contaminant in a volume of $1.0 \mathrm{ml}$ deionized water. Following 30 days of exposure to their respective lead doses, females were bred to nonexposed males. Males were removed from the home cage once females tested positive for copulatory plugs. Females continued to receive their daily doses of lead acetate throughout the gestational and lactation periods. Standard rat chow and tap water were available in the home cage.

Litters were culled to eight pups seven days after parturition rather than earlier to permit a more reliable sex determination of pups via visual inspection of genital spacing. Thirty-four males pups from 19 dams exposed daily to $0 \mathrm{mg}$ lead acetate, 32 male pups from 23 dams exposed to $8 \mathrm{mg}$ lead acetate, and 34 male pups from 15 dams exposed to $16 \mathrm{mg}$ lead acetate were included in the investigation. The remaining pups were used in other research projects. Of the total of 100 pups used in this study, approximately half began testing on PND 30 and half began testing on PND 90 (see below). During lactation, except for the day of parturition, dams continued to be gavaged daily with their respective lead doses. The resulting procedure permitted perinatal lead exposure within an experimental framework where pups were unable to gain access to lead postnatally via routes other than the maternal milk supply.

On PND 21, pups were weaned and for the remainder of the study placed on ad libitum standard rat chow diets, and they had continuous access to a tap water supply that contained no added lead. All animals were individually housed from PND 21 until the study was completed. Prior to weaning, food intake and body weight readings were recorded weekly for dams and pups, and postweaning pup food intake and weight measures were recorded daily for the remainder of the study. For the dams, 100-150 $\mu \mathrm{l}$ of tail-blood was drawn on the day prior to commencing lead exposure, and again at breeding, parturition, and weaning.

\section{Procedure}

Male pups from each of the three exposure conditions $(0,8$, and $16 \mathrm{mg}$ lead acetate) were stratified according to body weight. Within given weight ranges, pups were randomly assigned to commence testing on PND 30 or PND 90. The selection of doses was made on the basis of pilot investigations that yielded blood lead levels falling within a clinically relevant range $(\approx 35 \mu \mathrm{g} / \mathrm{dl}$ or less). Because animals gained weight during the period of lead exposure, a functionally decreasing dosing regimen was employed in a manner simulating what is likely in the developing human population. The test apparatus involved an automated Digiscan-16 system. (Omnitech Electronics, Inc., Columbus, OH). Activity monitors and cages were located in a sound-proof room with a $40 \mathrm{~dB}$ [SPL] white noise generator operating continuously. A multiplexor-analyzer in an adjacent room monitored beam breaks from the optical beam activity monitors and tracked the simultaneous interruption of beams. The multiplexor-analyzer updated the animal's position in the acrylic cage $(40 \times 40 \times 30.5 \mathrm{~cm})$ every 10 ms using a $100 \%$ real-time conversion system. Computerized integration of the data obtained from the monitor afforded the recording of general activity using total distance (in $\mathrm{cm}$ ) as the dependent measure.

In an effort to control for possible litter effects (cf., 
Holson and Pearce 1992), only one male pup per litter was placed in a given test condition. Animals that began activity testing on PND 30 were randomly selected and then randomly assigned to one of six test groups created by interacting lead-exposure condition $(0,8,16$ $\mathrm{mg}$ ) and type of injection (vehicle, cocaine). Animals receiving cocaine were administered daily i.p. injections of $10 \mathrm{mg} / \mathrm{kg}$ cocaine $\mathrm{HCl}$ expressed as the salt, whereas vehicle controls received saline $(1.0 \mathrm{ml} / \mathrm{kg}$ volume). In this initial phase of the project, animals were tested during $1 \mathrm{hr}$ sessions each day for 14 successive days, in squads of four, counterbalancing by group. With the room lights off, animals were placed in their respective test chambers for a 20-min baseline-recording period prior to receiving either a cocaine or vehicle-only injection. At the point of the injection, the room lights were turned on and the animal was placed back in the chamber immediately following the injection, at which time the room lights again were turned off. This procedure was employed in order to increase the discriminatory properties of the injections.

Previous cocaine investigations (e.g., Post et al. 1981) have shown that contextual cues contribute to augmented responding associated with repeated drug administration. Insofar as administering the injections, placement in the test chambers, turning off the test room lights and other pre-injection correlates serve in a feed-forward capacity (as CSs), it is reasonable to assume that reinstatement of such events could play an additive role in behavioral sensitization. We tested such a possibility by administering a vehicle only $(0 \mathrm{mg} / \mathrm{kg}$ cocaine) injection following initial sensitization testing (see procedures for Day 15 of testing). In all tests conducted in this study, total distance traveled $(\mathrm{cm})$ was recorded post-injection across successive 5-min intervals for $40 \mathrm{~min}$.

On Days 15-18, all animals within each of the six groups received successive daily i.p. injections of 0,10 , 20 , and $40 \mathrm{mg} / \mathrm{kg}$ cocaine. This range of cocaine doses has been shown to be sufficient to characterize the complete dose-effect function produced by increasing doses of the drug (Nation et al. 1995). Finally, as described in detail elsewhere (Nation et al. 1997), atomic absorption spectrophotometry procedures were used to determine blood lead concentrations in samples drawn from littermates as well as subjects sacrificed $24 \mathrm{hr}$ after the final day of testing,

Separate groups of animals that begin testing on PND 90 for sensitivity to the stimulatory effects of cocaine were tested precisely according to the procedures outlined for PND 30 testing. That is, type of injection (vehicle, cocaine), drug dose, injection procedures, dose-effect determinations, sample collection, and all other aspects of testing and recording operations were carried out exactly as described for animals assigned to the PND 30 test condition.
Analysis of variance (ANOVA) tests were performed on litter size, body weight and food intake, the behavioral data, and the blood lead level data. In all cases throughout this report, Neuman-Keuls procedure for examining significant mean differences was employed as the post hoc test.

\section{RESULTS}

\section{Litter Size}

An analysis performed on litter size yielded a significant group main effect $(\mathrm{F}(2,48)=3.08, p<.05)$. Post hoc comparisons revealed that there was a significant decrease in litter size among $16 \mathrm{mg}$ dams (mean $=10.8$ pups, SEM $= \pm 1.3$ ) compared to either control dams (mean $=12.9$ pups, SEM $= \pm 0.6$ ) or $8 \mathrm{mg}$ dams (mean = 12.1 pups, $\mathrm{SEM}= \pm 0.6$ ) which did not differ. In all cases, there were at least eight pups in the litter and culling took place as needed according to the procedures outlined above.

\section{Body Weights and Food Intake}

With respect to dam body weights, the univariate analysis of variance (ANOVA) tests performed on Group (control, $8 \mathrm{mg}$ lead, $16 \mathrm{mg}$ lead) failed to reveal evidence of significant group separation at the commencement of lead exposure or at breeding. Similarly, the Group $\times$ Weeks ANOVA test of differences in food consumption showed no treatment main effect or interaction effect.

Although pup body weights and food intake were recorded daily, weekly averages of individual body weight and food intake were used as the dependent measure in the analyses. In order to compare the initial performances of animals commencing behavioral testing at PND 30 and animals commencing testing at PND 90, separate three Groups $(0,8,16 \mathrm{mg}$ lead $) \times 2$ Testing Periods (PND 30, PND 90), ANOVAs were performed on pup body weights and food intake. The analysis of mean body weights during the post-weaning period prior to testing yielded a significant groups main effect $(F(2,88)=18.53, p<.01)$. Post hoc analyses showed that control animals weighed significantly more than either the $8 \mathrm{mg}$ lead animals or the $16 \mathrm{mg}$ lead animals, which did not differ; $p<.05$ [means and SEM values were; control $(0 \mathrm{mg}$ lead $)=152.1 \pm 11.7 \mathrm{~g}, 8 \mathrm{mg}$ lead $=127.3 \pm$ $8.8 \mathrm{~g}, 16 \mathrm{mg}$ lead $=122.5 \pm 8.5 \mathrm{~g}]$. However, tests of the Testing Period main effect and the interaction were found to be nonsignificant $(\mathrm{Fs}<1)$.

In contrast to the body weight data, the analysis of group separation on the measure of mean food intake failed to show significant mean differences. And, once again no significant effects associated with testing period were found $(F s<1)$. These findings seemingly rule 
out the possibility of an inadvertent sampling bias between the groups of animals tested beginning on either PND 30 or PND 90.

For those animals that began testing on PND 90, the Groups $\times$ Weeks repeated measures analysis performed on mean weekly body weights failed to reveal evidence of significant group separation at any point prior to testing $(\mathrm{F}<1)$ [control $=534.9 \pm 15.5 \mathrm{~g}, 8 \mathrm{mg}$ lead $=530.6 \pm 13.6 \mathrm{~g}, 16 \mathrm{mg}$ lead $=528.8 \pm 7.6 \mathrm{~g}]$. An identical analysis of mean weekly food intake yielded a nonsignificant group main effect, but the Group $\times$ Week interaction was found to be significant $(F(12,282)=$ $1.96, p<.05)$. Post hoc comparisons indicated that food consumption was greater for control animals than either of the lead-exposed groups on weeks 4 and 6 postweaning $(p<.05)$. None of the groups were significantly different in terms of food intake during the week prior to commencing testing.

\section{Behavioral Data}

The findings from this investigation of developmental lead effects on cocaine challenges presented later in the adult cycle showed that the toxicant altered behavioral responsiveness to the stimulatory effects of the drug long after the exposure regimen had been discontinued.

Pre-injection (baseline) and post-injection activity profiles of animals commencing testing on PND 30 are graphically depicted in Figure 1. The differential nature of lead-related changes in the behavioral response to cocaine is apparent from a visual inspection of the data. Statistical confirmation of these differences was provided by findings from separate Group $\times 5$-min intervals repeated measures ANOVAs performed on the data from Day 1, Day 7, and Day 14. Baseline responding was not found to be different across groups at any point. With respect to the initial, acute $10 \mathrm{mg} / \mathrm{kg}$ cocaine challenge on Day 1, group differences were found $(\mathrm{F}(35,301)=5.18, p<.01)$. Post hoc analyses revealed that the activity-increasing effects of the drug were significantly less pronounced in animals perinatally exposed to dams receiving daily doses of $8 \mathrm{mg}$ or $16 \mathrm{mg}$ lead acetate $(p<.05)$. While repeated administration produced behavioral sensitization to the stimulatory effects of cocaine in all drug-treated groups by Day 14 $(\mathrm{F}(35,301)=8.95, p<.01)$, post hoc tests indicated that $\begin{array}{ll}\text { Day } 1 & \text { Day } 7\end{array}$

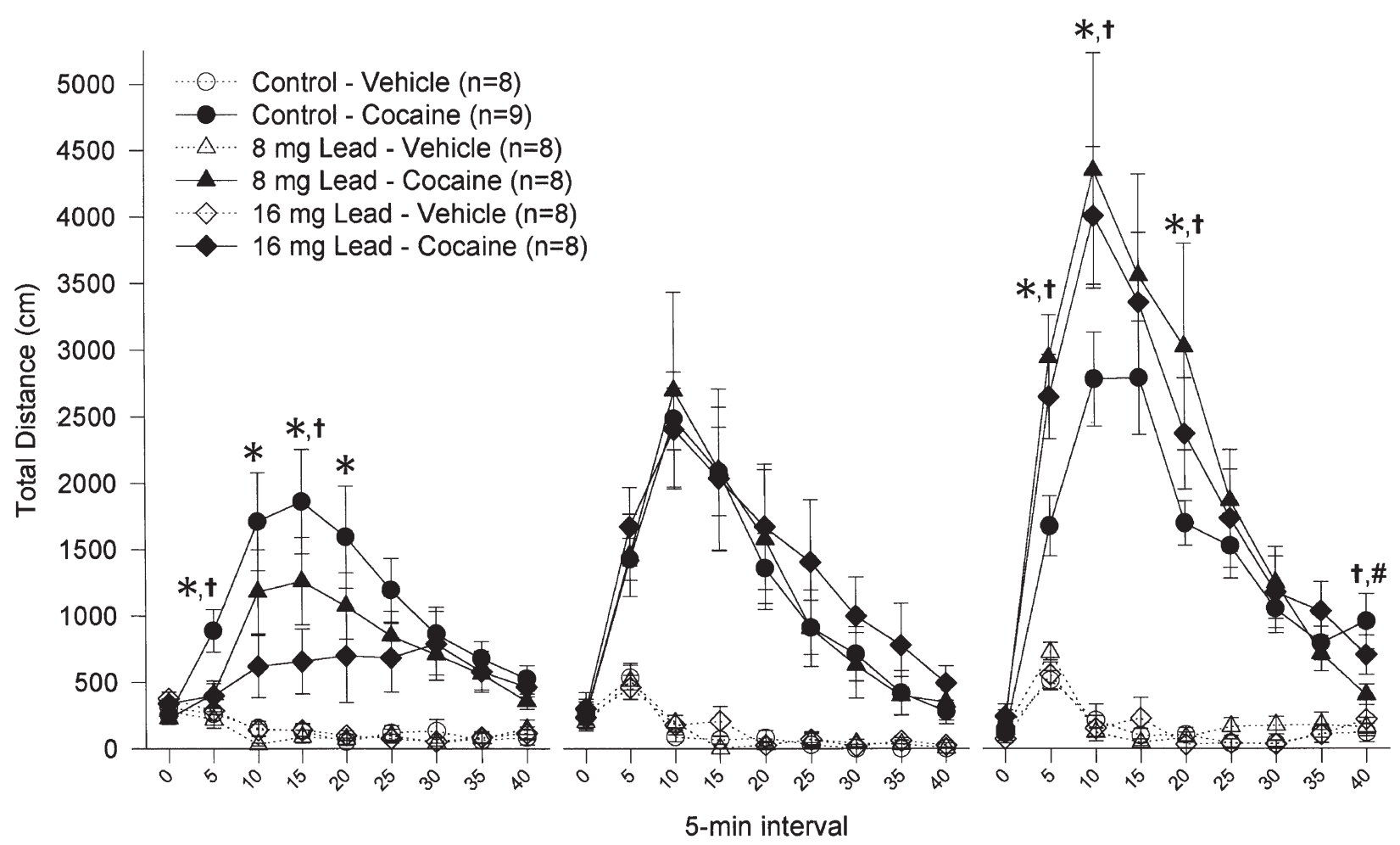

Figure 1. The mean ( \pm S.E.M.) total distance traveled $(\mathrm{cm})$ across successive 5 -min intervals for animals perinatally exposed to dams receiving 0 (control), 8, or $16 \mathrm{mg}$ lead acetate (Days 1, 7, and 14 of behavioral sensitization testing commencing on PND 30). A vehicle only injection or a $10 \mathrm{mg} / \mathrm{kg}$ cocaine challenge was presented immediately following the final 5-min baseline period (point 0 ). The following symbols denote significant group separation $(p<.05$ ): * $=$ Group 16 mg Lead-Cocaine different from Group Control-Cocaine; $+=$ Group $8 \mathrm{mg}$ Lead-Cocaine different from Group Control-Cocaine; \# = Group $16 \mathrm{mg}$ Lead-Cocaine different from Group $8 \mathrm{mg}$ Lead-Cocaine. 

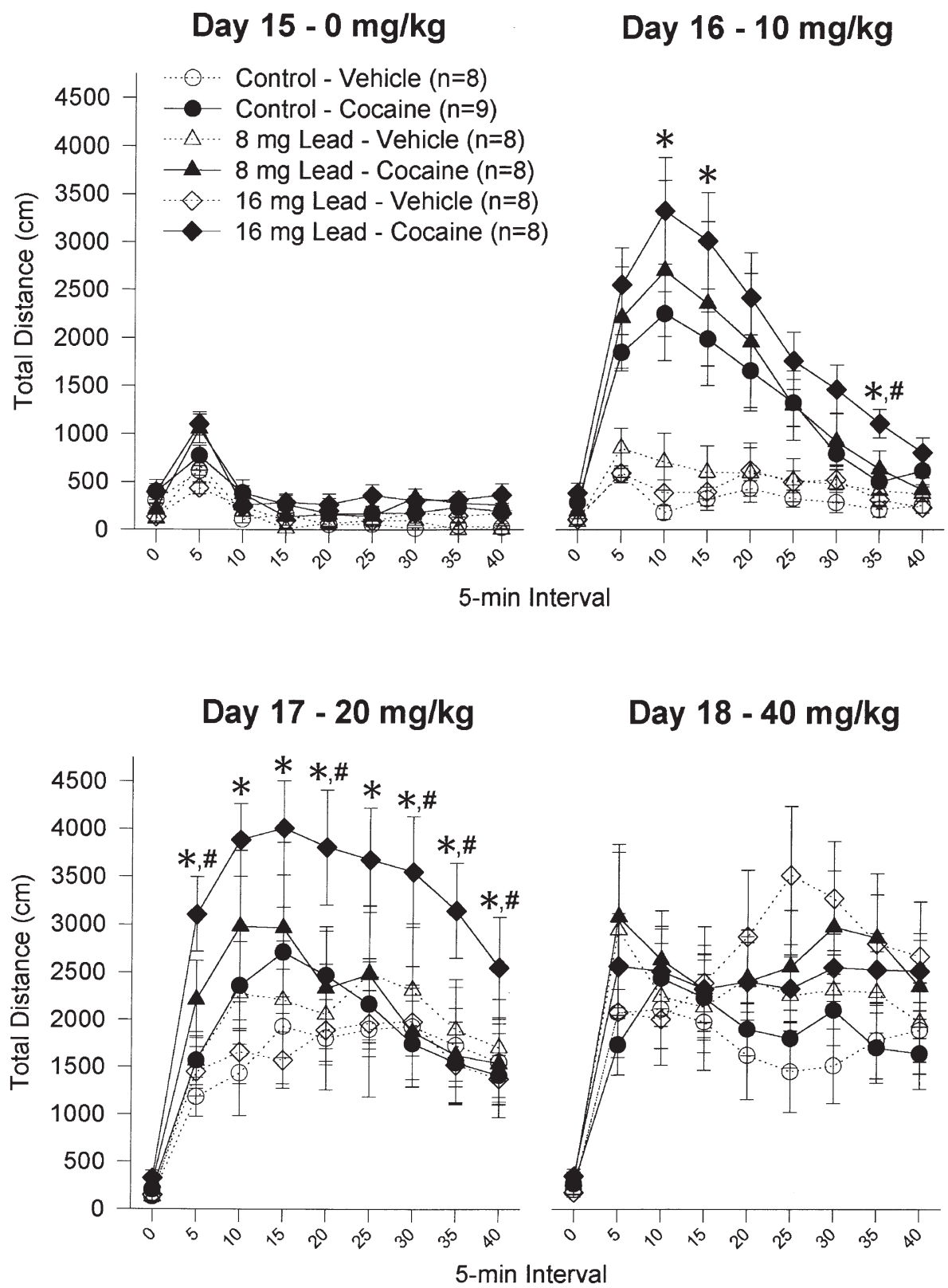

Figure 2. After PND 30 behavioral sensitization testing, the mean ( \pm S.E.M.) total distance traveled (cm) across successive 5-min intervals for animals perinatally exposed to dams receiving 0 (control), 8 , or $16 \mathrm{mg}$ lead acetate. Ascending test doses of $0,10,20$, or $40 \mathrm{mg} / \mathrm{kg}$ cocaine were presented daily to each animal immediately following the final 5-min baseline period (point 0 ). The following symbols denote significant group separation $(p<.05): *=$ Group $16 \mathrm{mg}$ LeadCocaine different from Group Control-Cocaine; \# = Group $16 \mathrm{mg}$ Lead-Cocaine different from Group $8 \mathrm{mg}$ Lead-Cocaine. the effect was significantly greater in the lead-exposed groups $(p<05)$.

Supporting evidence was obtained from the analysis of the dose-effect data (Figure 2), where the triple interaction test resulting from a Group $\times$ Dose $\times 5$-min intervals repeated measures ANOVA was found to be significant $(\mathrm{F}(105,903)=1.53, p<.01)$. Post hoc analyses revealed that animals exposed to $16 \mathrm{mg}$ lead, but not $8 \mathrm{mg}$ lead, were more responsive than controls to 10 $\mathrm{mg} / \mathrm{kg}$ cocaine and $20 \mathrm{mg} / \mathrm{kg}$ cocaine; $p<.05$ [baseline responding was not different across groups]. Indeed, at the $20 \mathrm{mg} / \mathrm{kg}$ dose $(\mathrm{F}(15,129)=1.93, p<.05)$, the relevant post hoc tests showed that $16 \mathrm{mg}$ lead animals exhibited greater activity than controls even when collapsing across all 5-min intervals $(p<.05)$.
At the $40 \mathrm{mg} / \mathrm{kg}$ test $(\mathrm{F}(15,129)=1.93, p<.05)$, post hoc analyses revealed that lead-exposed and control animals that had previously received cocaine pretreatments during the test for sensitization were not significantly different, as responding had decreased for the 16 mg Lead-Cocaine animals at this highest cocaine dose. What is perhaps of greater interest at the $40 \mathrm{mg} / \mathrm{kg}$ dose is that $16 \mathrm{mg}$ lead animals that had received repeated vehicle-only injections during sensitization testing (16 mg Lead-Vehicle) showed significantly greater post-injection activity across 5 -min intervals relative to control animals that had received repeated vehicle-only experiences $(p<.05)$. Thus, it would seem that even in the absence of a substantial drug history, early lead exposure promotes enhanced reactivity to cocaine at PND 


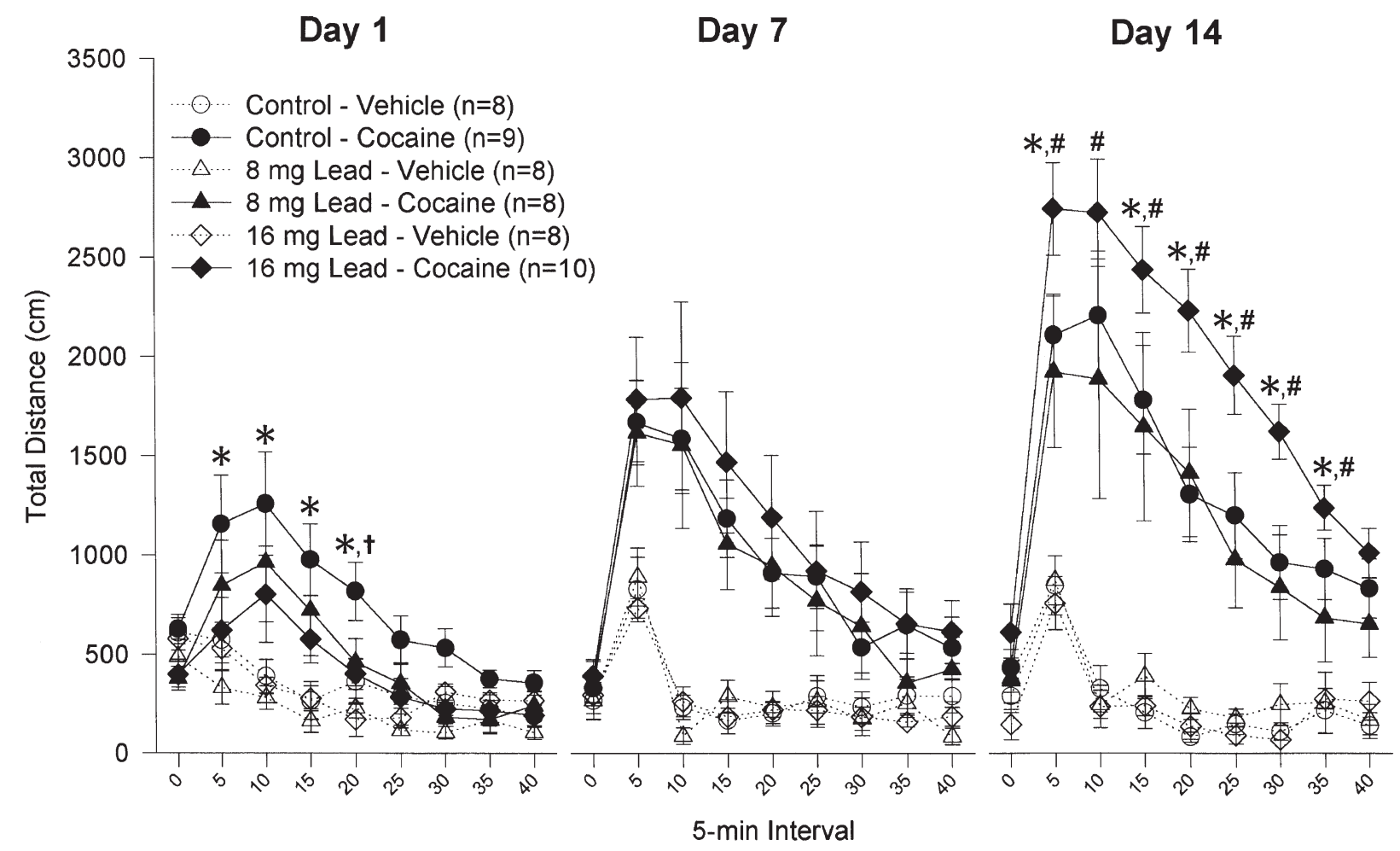

Figure 3. The mean ( \pm S.E.M.) total distance traveled $(\mathrm{cm})$ across successive 5 -min intervals for animals perinatally exposed to dams receiving 0 (control), 8, or $16 \mathrm{mg}$ lead acetate (Days 1, 7, and 14 of behavioral sensitization testing commencing on PND 90). A vehicle only injection or a $10 \mathrm{mg} / \mathrm{kg}$ cocaine challenge was presented immediately following the final 5-min baseline period (point 0 ). The following symbols denote significant group separation $(p<.05$ ): * $=$ Group 16 mg Lead-Cocaine different from Group Control-Cocaine; ${ }^{\dagger}=$ Group $8 \mathrm{mg}$ Lead-Cocaine different from Group Control-Cocaine; \# = Group $16 \mathrm{mg}$ Lead-Cocaine different from Group $8 \mathrm{mg}$ Lead-Cocaine.

47 (40 mg/ $\mathrm{kg}$ test day). Finally, it is noted that none of the groups differed substantially on Day 15 when 0 $\mathrm{mg} / \mathrm{kg}$ cocaine injections were administered. Thus, it did not appear that context was an important contributor to the pattern of results obtained here.

The behavioral sensitization data obtained for activity testing that began on PND 90 are presented in Figure 3. Baseline responding did not differ across groups. It is visually apparent from Figure 3 that the post-injection findings from PND 90 essentially paralleled those observed for testing operations that began on PND 30. That is, even though lead exposure had been discontinued at weaning, at 90 days of age animals from the 16 mg exposure condition, but not the $8 \mathrm{mg}$ exposure condition, expressed a subsensitivity to an acute challenge of $10 \mathrm{mg} / \mathrm{kg}$ cocaine (Day 1 of testing), and a supersensitivity to the sensitizing effects associated with repeated drug administration (Day 14 of testing). Statistical confirmation of these lead-induced changes in responsiveness to cocaine was provided by the results of interaction analyses performed on Day $1(\mathrm{~F}(35,315)=$ $2.64, p<.01)$ and Day $14(\mathrm{~F}(35,315)=3.71, p<.01)$, and the appropriate post hoc tests.
Further evidence of augmented responsiveness to the motor-stimulating properties of repeated cocaine administration in PND 90 animals perinatally exposed to lead is available from an examination of the doseeffect data (Figure 4). With no baseline differences at any dose, at the dose of $20 \mathrm{mg} / \mathrm{kg}(\mathrm{F}(105,945)=1.91$, $p<.01$ ), post hoc analyses indicated that a supersensitivity to the drug was evident in both lead-exposed conditions previously administered cocaine repeatedly during sensitization testing, and a similar pattern was apparent among $16 \mathrm{mg}$ lead animals at a dose of 40 $\mathrm{mg} / \mathrm{kg}(p<.05)$. These triple interaction comparisons were supported by post hoc results showing that groups $8 \mathrm{mg}$ lead and $16 \mathrm{mg}$ lead exhibited greater activity collapsing across all 5-min intervals at the 20 $\mathrm{mg} / \mathrm{kg}$ dose $(\mathrm{F}(15,135)=1.95, p<.05)$, and this pattern was still evident at the $40 \mathrm{mg} / \mathrm{kg}$ dose for the $16 \mathrm{mg}$ lead animals $(p<.05)$. As was the case at PND 30, context (the $0 \mathrm{mg} / \mathrm{kg}$ cocaine challenge on Day 15) did not appear to play a prominent role in the effects observed for PND 90 animals.

Although there was a tendency for the lead-exposed vehicle only animals to once again show an augmented 


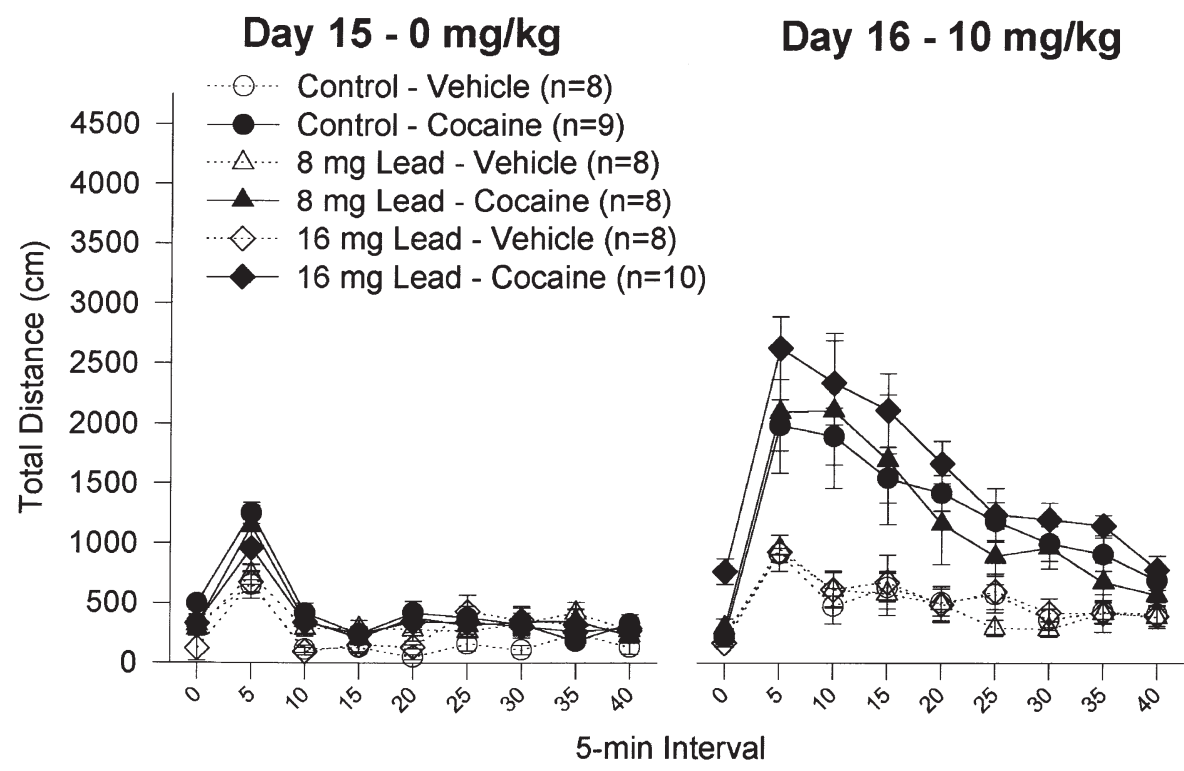

Day 17 - $20 \mathrm{mg} / \mathrm{kg}$

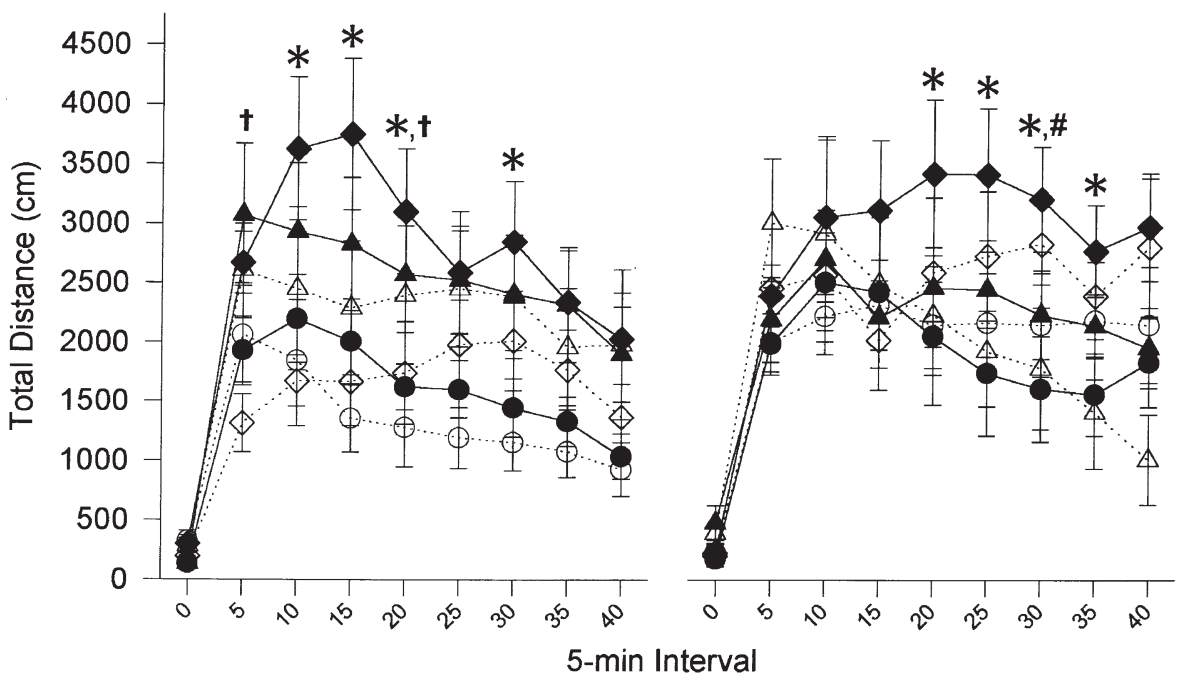

Figure 4. After PND 90 behavioral sensitization testing, the mean ( \pm S.E.M.) total distance traveled (cm) across successive 5-min intervals for animals perinatally exposed to dams receiving 0 (control), 8 , or $16 \mathrm{mg}$ lead acetate. Ascending test doses of $0,10,20$, or $40 \mathrm{mg} / \mathrm{kg}$ cocaine were presented daily to each animal immediately following the final 5-min baseline period (point 0 ). The following symbols denote significant group separation $(p<.05):{ }^{*}=$ Group $16 \mathrm{mg}$ LeadCocaine different from Group Control-Cocaine; ${ }^{\dagger}=$ Group $8 \mathrm{mg}$ LeadCocaine different from Group Control-Cocaine; \# = Group $16 \mathrm{mg}$ Lead-Cocaine different from Group $8 \mathrm{mg}$ Lead-Cocaine. response to the cocaine challenges presented during dose-effect testing, the group differences were not significantly different for animals commencing testing at PND 90.

\section{Blood Lead Levels}

Regarding metal concentrations in dams at breeding, parturition, and weaning, blood lead levels were ordered by exposure amount $(\mathrm{F}(2,55)=653.41, p<.01)$. Neither the main effect for Time of Sampling nor the Groups $\times$ Time of Sampling interaction were significant. Blood lead residues greater than $1 \mu \mathrm{g} / \mathrm{dl}$ were not detected in any dam prior to introducing the exposure regimen. At breeding, parturition, and weaning blood lead was below the limits of detection $(<1 \mu \mathrm{g} / \mathrm{dl})$ for controls ( $0 \mathrm{mg} / \mathrm{kg}$ condition). Post hoc tests showed that elevated blood lead concentrations were evident among dams exposed daily to $8 \mathrm{mg}$ lead acetate (16.6士 $4.0 \mu \mathrm{g} / \mathrm{dl}, 22.0 \pm 4.5 \mu \mathrm{g} / \mathrm{dl}$, and $23.0 \pm 5.1 \mu \mathrm{g} / \mathrm{dl}$ at breeding, parturition, and weaning, respectively), and metal concentrations were significantly greater in 16 $\mathrm{mg}$ lead acetate dams than either of the other exposure conditions $(32.5 \pm 1.4 \mu \mathrm{g} / \mathrm{dl}, 31.0 \pm 4.9 \mu \mathrm{g} / \mathrm{dl}$, and $33.9 \pm$ $0.4 \mu \mathrm{g} / \mathrm{dl}$ at breeding, parturition, and weaning, respectively $(p<.05)$.

Analyses of blood in paired littermates at PND Day 1 $(\mathrm{F}(2,18)=7.14, p<.01)$ revealed that lead concentrations were below the limits of detection in controls, $12.3 \pm$ $2.1 \mu \mathrm{g} / \mathrm{dl}$ in $8 \mathrm{mg}$ pups, and $21.8 \pm 2.6 \mu \mathrm{g} / \mathrm{dl}$ in $16 \mathrm{mg}$ 
pups. Post hoc analyses indicated that each of the three groups were significantly different from each other $(p<.05)$. At PND $30(\mathrm{~F}(2,47)=5.02, p<.01)$, lead concentrations in littermates were below detectable levels in control and $8 \mathrm{mg}$ pups, but remained slightly elevated $[5.0 \pm 0.8 \mu \mathrm{g} / \mathrm{dl}]$ in $16 \mathrm{mg}$ pups $(p<.05)$. For animals used in the study, blood lead levels in metal-exposed pups were all below the limits of detection at the conclusion of PND 30 and PND 90 testing. Ostensibly, clearance from soft tissue was complete even by the end of PND 30 testing, yet profound changes in the behavioral sensitivity to cocaine persisted for long periods after elimination of blood lead was accomplished.

\section{DISCUSSION}

Various prospective human studies (Bellinger et al. 1987; Needleman et al. 1996), and corroborating reports from the animal literature (Banks et al. 1997; Rice 1996), demonstrate reliably that the developing organism is especially vulnerable to low-level lead exposure. Impaired cognitive and attentional processes, performance compromises, and increased social aggression are listed among the behavioral sequelae associated with blood lead levels that only a few years ago were deemed "acceptable" (Brody et al. 1994; Goldman and Carra 1994; Needleman et al. 1996). In this report, the first to examine lead/cocaine interactions within a developmental context, we show that clinically relevant levels of metal contamination presented during pregnancy and immediately following birth also alter responsiveness to a drug that possesses substantial abuse liability. That such behavioral shifts were evident in the adult well after discontinuation of exposure is suggestive of long-lasting, potentially nonreversible change.

The finding observed here of lead-induced attenuation of the motor activating properties of an acute challenge of cocaine in developmentally-exposed animals agrees with previous studies from our laboratory regarding the adult lead-exposure case. Specifically, in a study where male rats were exposed as adults to a water supply containing 500-ppm lead acetate, cocainerelated increases in activity were reduced relative to non-exposed controls (Grover et al. 1993; Nation et al. 1996). In addition, in a subsequent investigation of the effects of cocaine on schedule-controlled responding, adult animals exposed to lead were found to be less responsive to the rate-enhancing effects of cocaine (Burkey et al. 1997). Consistent with this pattern of diminished behavioral sensitivity to cocaine in the adult lead-exposure case, cocaine-induced elevation of nucleus accumbens dopamine levels is attenuated by chronic lead exposure in the adult (Nation and Burkey 1994). Indeed, given that diminished mesolimbic dopamine synthesis is evident in lead-exposed adults even in the absence of a drug challenge (Lasley and Lane 1988), metal-based antagonism of behavioral responsiveness to cocaine would be expected, at least insofar as dopamine availability and consequent regulatory changes are integral to the development and expression of cocaine effects (Hemby et al. 1999; Wise and Bozarth 1987).

It is noteworthy that the apparent pattern of leadinduced antagonism of the neurochemical and behavioral effects of cocaine that we have observed in the adult animal is consistent with the early findings reported by other investigators who examined lead/ $d$-amphetamine interactions. Both the locomotor stimulating and the discriminative properties of amphetamine have been found to be attenuated by chronic lead exposure (Rosen et al. 1986; Silbergeld and Goldberg 1980; Zenick and Goldsmith 1981). Collectively, then, the emergent pattern is one of lead-based antagonism of psychostimulant sensitivity.

Within this context, the dramatic result of enhanced sensitivity to repeated administration of cocaine in perinatally-exposed pups is somewhat surprising. Prominent even when testing commenced on PND 90, this supersensitivity effect clearly is at odds with the aforementioned adult data where decreased responsiveness to cocaine is apparent even with repeated drug challenges (Nation et al. 1996). Yet, as striking as these directional shifts may be, they are not uncommon in neurobehavioral comparisons involving developing and mature organisms. Regarding modulatory neurochemical operations, for instance, several reports have shown that changes in mesolimbic and striatal dopamine receptor binding are linked to the developmental period during which repeated cocaine or lead exposure occurs. Repeated exposure to cocaine in adulthood produces a decrease in $D_{1}-D_{2}$ receptors in the nucleus accumbens, as well as a decrease in $G$ protein subunits coupled to these receptors (Dow-Edwards 1989). In contrast, neonatal exposure to cocaine results in a long-term increase in dopamine receptor binding (Scalzo et al. 1990). Perhaps more directly related to our behavioral findings, postnatal lead exposure facilitates $D_{1}$ and $D_{2}$ receptor number development in the striatum and nucleus accumbens (Widzowski et al. 1994), but dopamine binding sites are selectively decreased in the nucleus accumbens of the lead-exposed adult (Pokora et al. 1996).

Apart from comparative differences in perinatal or adult lead exposure, perhaps a more intriguing issue is the differential impact of acute or repeated cocaine administration in pups developmentally exposed to lead. Along these lines, the expansive literature on changes that occur in brain morphology and function during periadolescence is especially relevant. It is established that the rat brain undergoes dramatic changes during the 10 days that precede the onset of puberty at about Day 40 (Teicher et al. 1995, 1998). Perhaps, most con- 
spicuous in this regard, is the marked overproduction of synaptic receptors, and the subsequent profound elimination ("pruning") of these synaptic contacts during the transition from adolescence to adulthood (Andersen et al. 1997; Teicher et al. 1995). Although, the functional importance of synaptic elimination is not known, it is obvious that selective changes in receptor density and binding in brain regions rich in dopamine (dorsal and ventral striatum, prefrontal cortex) may influence drug sensitivity (Andersen et al. 1997).

Precisely how metal exposure may affect such ontogenetic changes in neural activity is unknown. It is possible that early lead exposure may alter the course and eventual fate of the serial processes of synaptic proliferation and elimination that occur during periadolescence, and therein contribute to changes in sensitivity to drug activities mediated by prominent changes in receptor binding. Believed to be orchestrated by a single genetic or hormonal signal (Teicher et al. 1995), it is possible that heavy metal contamination during the period of early development may alter the normal process of ontogeny and redefine the configuration of the circuitry that ultimately determines responsiveness to cocaine. Conversely, metal-based changes in transmitter bioavailability following acute or repeated drug administration may result in a behavioral pattern of cocaine subsensitivity followed by a period of cocaine supersensitivity.

With respect to the possibility of such disturbances in ontogenetic development in lead-exposed animals, the data from pups presented with the vehicle only during sensitization testing may be instructive. For those animals commencing testing at PND 30, there was some indication that among vehicle-only animals the group perinatally exposed to lead via dams receiving $16 \mathrm{mg}$ lead acetate daily were more responsive to cocaine during dose-effect testing. This pattern of separation would suggest that biochemical or neuroanatomical changes during periadolescent development were induced by developmental lead exposure apart from drug experience. Within this framework, the greater effects observed here in animals repeatedly administered cocaine could be interpreted as being due to a potentiating factor that simply augments increased transmitter availability and/or synaptic proliferation otherwise associated with developmental lead exposure. The problem with this rationale, of course, is that it fails to satisfactorily address the issue of blunted reactivity to acute cocaine administration at PND 90.

Related to the issue of the differential effects of cocaine on the performance of animals that had received vehicle only during the initial sensitization testing period, is the fact that no attenuation to the first administration of $10 \mathrm{mg} / \mathrm{kg}$ cocaine was evident among leadexposed vehicle-only animals relative to controls (Day 16; Figures 2 and 4). That is, unlike the experimentally naive animals that began testing at PND 30 or PND 90, the $8 \mathrm{mg}$ and $16 \mathrm{mg}$ lead animals that had received repeated vehicle injections prior to receiving their first (acute) cocaine challenge exhibited response patterns essentially parallel those of controls $(0 \mathrm{mg})$. Because the lack of lead-related attenuation of the effects of an acute cocaine challenge was apparent both in PND 30 animals and PND 90 animals that had received vehicleonly injections, it is difficult to render an interpretation of this finding based on an appeal to age-related variables per se. Rather, it would seem that context experiences, associative phenomena, multiple injections, and/ or other aspects of testing altered the pattern of diminished responsiveness to cocaine that otherwise occurs in animals perinatally exposed to lead when they have no history in the environmental test chamber. Whatever the mechanism, it is worth noting that precisely the same pattern of lead-related attenuation of responsiveness to an acute cocaine challenge in experimentally naive animals, but no such attenuation in vehicle-only animals, occurs with adult lead exposure (Nation et al. 1996).

Numerous other issues relating to dynamics and scope must be resolved. In the absence of information on disturbances in cocaine pharmacokinetics following developmental lead exposure, it is not possible to rule out differences in drug distribution or metabolism in our lead-exposed and control animals. That is, although we know that in the adult case lead exposure alters responsiveness to cocaine even when brain and plasma concentrations of cocaine and benzoylecgonine are comparable to control levels (Nation et al. 1997), no data on the topic are available from developmental studies. Thus, non-neuronal mechanisms may be responsible for the effects observed here. Also, gender differences are often noted in cocaine sensitization studies (e.g., Laviola et al. 1995), and it would be of interest to compare male/female pups perinatally exposed to lead and repeatedly challenged with cocaine. Too, there is the issue of idiosyncratic early dam/pup experiences that may have been produced by perinatal lead exposure. It is possible that lead-related changes in maternal behavior and care may have had an impact on the outcome of our experiments. In this regard, the need for a more systematic appraisal of the relative contributions of prenatal (gestation) or postnatal (lactation) exposure to lead-based changes in cocaine sensitivity is indicated. Cross-fostering pups would not only yield useful information about a potential critical period or developmental window for lead/cocaine effects, it would also address issues surrounding the possible indirect impact of lead exposure on dam/offspring interactions during the first days of development.

In closing, it is apparent from this report that the changes in responsiveness to cocaine produced by developmental lead exposure persist in the adult long af- 
ter systemic clearance of the metal is gained. While arguments can be made that such preclinical findings may provide a valid basis for sensitive prediction of drug abuse liability in humans (cf., Mello et al. 1995), statements about possible linkages between environmental pollution and drug selection/taking must be made cautiously until more data are available from this under-explored area.

\section{ACKNOWLEDGMENTS}

Public Health Service Grant DA07932 supported this research.

\section{REFERENCES}

Andersen SL, Rutstein M, Benzo JM, Hostetter JC, Teicher $\mathrm{MH}$ (1997): Sex differences in dopamine receptor overproduction and elimination. NeuroReport 8:1495-1498

Banks EC, Ferretti LE, Shucard DW (1997): Effects of lowlevel lead exposure on cognitive function in children: A review of behavioral, neuropsychological, and biological evidence. Neurotoxicology 18:237-282

Bellinger D, Leviton A, Waternaux C, Needleman H, Rabinowitz M (1987): Longitudinal analyses of prenatal and postnatal lead exposure and early cognitive development. N Engl J Med 316:1037-1043

Brody DJ, Pirkle JL, Kramer RA, Flegal KM, Matte TD, Gunter EW, Paschal DC (1994): Blood lead levels in the US population: Phase 1 of the Third National Health and Nutrition Examination Survey (NHANES III, 19881991). JAMA 272:277-283

Burkey RT, Nation JR, Grover CA, Bratton GR (1997): Effects of chronic lead exposure on cocaine-induced disturbance of fixed-interval behavior. Pharmacol Biochem Behav 56:117-121

Dow-Edwards DL (1989): Long-term neurochemical and neurobehavioral consequences of cocaine abuse during pregnancy. Ann NY Acad Sci 562:280-289

Goldman LR, Carra J (1994): Childhood lead poisoning in 1994. JAMA 272:315-316

Grover CA, Nation JR, Bratton GR (1993): Chronic exposure to lead attenuates cocaine-induced behavioral activation. Pharmacol Biochem Behav 44:221-225

Hemby SE, Co C, Dworkin SI, Smith JE (1999): Synergistic elevation in nucleus accumbens extracellular dopamine concentrations during self-administration of cocaine/ heroin combinations (speedball) in rats. J Pharmacol Exper Therap 288:274-280

Holson RR, Pearce B (1992): Principals and pitfalls in the analysis of prenatal treatment effects in multiparous species. Neurotoxicol Teratol 14:221-228

Lasley SM, Lane JD (1988): Diminished regulation of mesolimbic dopaminergic activity in the rat after chronic lead exposure. Toxicol Appl Pharmacol 95:474483

Laviola G, Wood RD, Kuhn C, Francis R, Spear L (1995):
Cocaine sensitization in periadolescent and adult rats. J Pharmacol Exper Therap 275:345-357

Mello N, Negus S, Lukas SE, Mendelson JH, Sholar JW, Drieze J (1995): A primate model of polydrug abuse: Cocaine and heroin combinations. J Pharmacol Exper Therap 274:1325-1337

Mielke HW (1999): Lead in the inner cities. Am Sci 87:62-73

Nation JR, Burkey RT (1994): Attenuation of cocaineinduced elevation of nucleus accumbens dopamine in lead-exposed rats. Brain Res Bull 35:101-104

Nation JR, Livermore CL, Bratton GR (1995): Cadmium exposure attenuates the initiation of behavioral sensitization to cocaine. Brain Res 702:223-232

Nation JR, Livermore CL, Burkey RT (1996): Chronic lead exposure attenuates sensitization to the locomotor stimulating effects of cocaine. Drug Alcoh Depend 41:143149

Nation JR, Wellman PJ, Livermore CL, Miller DK, Bratton GR (1997): Brain and plasma levels of cocaine and benzoylecgonine in lead-exposed and cadmium-exposed rats following acute or chronic intraperitoneal administration of cocaine. Toxicol Lett 92:47-57

Needleman HL, Reiss JA, Tobin MJ, Biesecker GE, Greenhouse JD (1996): Blood lead levels and delinquent behavior. JAMA 275:363-369

Pirkle JL, Brody DJ, Gunter EW, Kramer RA, Paschal DC, Flegal KM, Matte TD (1994): The decline in blood lead levels in the United States. JAMA 272:284-291

Pokora MJ, Richfield EK, Cory-Slechta DA (1996): Preferential vulnerability of nucleus accumbens dopamine sites to low-level lead exposure: Time course of effects and interactions with chronic dopamine agonist treatment. J Neurochem 67:1540-1550

Post RM, Lockfield A, Squillace KM, Contel NR (1981): Drug-environment interaction: Context dependency of cocaine-induced behavioral sensitization. Toxicol Appl Pharmacol 81:755-760

Post RM, Weiss SRB, Pert A (1992): Sensitization and kindling effects of chronic cocaine administration. In Lakoski JM, Galloway MP, White, FJ (eds), Cocaine: Pharmacology, Physiology, and Clinical Strategies. Boca Raton, CRC Press, pp 115-161

Rice DC (1996): Behavioral effects of lead: Commonalties between experimental and epidemiological data. Envir Health Perspect 104:337-351

Robinson TE, Berridge KC (1993): The neural basis of drug craving: An incentive-sensitization theory of addiction. Brain Res Rev 18:247-291

Rosen JB, Young AM, Beuthin FC, Louis-Ferdinand RT (1986): Discriminative stimulus properties of amphetamine and other stimulants in lead-exposed and normal rats. Pharmacol Biochem Behav 24:211-215

Scalzo FM, Ali SF, Frambes NA, Spear LP (1990): Weaning rats exposed prenatally to cocaine exhibit an increase in striatal D2 binding associated with an increase in ligand affinity. Pharmacol Biochem Behav 37:371-373

Segal DS, Schuckit MA (1983): Animal models of stimulantinduced psychosis. In Creese I (ed), Stimulants: Neurochemical, Behavioral, and Clinical Perspectives. New York, Raven Press, pp 131-167 
Silbergeld EK, Goldberg AM (1980): Problems in experimental studies of lead poisoning. In Singhal RL, Thomas JA (eds), Lead Toxicity. Baltimore, MD, Urban and Schwartzberg, pp 19-41

Teicher MH, Andersen SL, Hostetter JC (1995): Evidence for dopamine receptor pruning between adolescence and adulthood in striatum but not nucleus accumbens. Dev Brain Res 89:167-172

Teicher MH, Dumont NL, Andersen SL (1998): The developing prefrontal cortex: Is there a transient interneuron that stimulates catecholamine terminals? Synapse 29:89-91

Widzowski DV, Finkelstein JN, Pokara MJ, Cory-Slechta DA
(1994): Time course of postnatal lead-induced changes in dopamine receptors and their relationship to changes in dopamine sensitivity. Neurotoxicology 15:853-866

Wise RA, Bozarth MA (1987): A psychomotor stimulant theory of addiction. Psychol Rev 94:469-492

Wolf ME, Dahlin SL, Hu X, White K (1995): Effects of lesions of prefrontal cortex, amygdala, or fornix on behavioral sensitization to amphetamine: Comparison with N-methyl-D-aspartate antagonists. Neuroscience 69:417-439

Zenick H, Goldsmith M (1981): Drug discrimination learning in lead-exposed rats. Science 212:569-571 